\title{
Impacto de las segregaciones municipales sobre los juzgados de aguas del Bajo Segura en el siglo XVIII
}

\author{
David Bernabé Gil \\ Dpto. de Historia Medieval, Historia Moderna y CC y TT HH. Universidad de Alicante \\ David.Bernabe@ua.es
}

\begin{abstract}
Resumen. La compleja articulación territorial de la jurisdicción de aguas en el Bajo Segura experimentó a lo largo de la edad moderna profundas modificaciones, que estuvieron relacionadas, en gran medida, con los procesos de segregación municipal y las colonizaciones señoriales desarrolladas en el término originario dependiente de la ciudad de Orihuela. En la presente comunicación se aborda el impacto que tuvieron sobre los juzgados de aguas de dicha zona las diversas modalidades que adoptó esa dinámica disgregadora, en virtud, fundamentalmente, de las peculiaridades que mostró la particular inserción de cada espacio concreto de irrigación dentro del complejo macrosistema constitutivo del Bajo Segura, pero con un especial detenimiento en el análisis del caso concreto de Rojales. Queda con ello de manifiesto cómo la ausencia de correlaciones estrictas entre los sistemas de acequias o azudes, por un lado, y los términos municipales, por otro, al extenderse cada uno de aquellos por varios de éstos, impidió la conformación de nuevos espacios jurisdiccionales cerrados, susceptibles de proyectarse íntegramente sobre la totalidad de los perímetros de irrigación correspondientes a cada unidad de derivación o de distribución de aguas.
\end{abstract}

Palabras Clave: segregaciones municipales, regadío, Bajo Segura, Edad Moderna, Rojales.

\begin{abstract}
The impact of the municipal segregation on the Courts of irrigation of Bajo Segura during the XVIII century. The complex territorial infrastructure of the irrigation in Bajo Segura underwent profound changes throughout the Modern Age, which were largely related to the municipal segregation process and territorial colonisations developed in the original municipal district of the city of Orihuela. This presentation deals with the impact that the various methods adopted by that fragmented dynamic had on the waters of the said zone, fundamentally with the peculiarities that the particular insertion of each specific irrigation displayed within the Bajo Segura complex constitutive macrosystem; paying special attention to analysing the specific case of Rojales town. This reflects how the absence of the strict correlations between the ditch or dam system on one hand, and the municipal districts on the other hand, each one spread over several of these, it impeded the establishment of new closed jurisdictional spaces susceptible to entirely projecting over the totality of the irrigation perimeters corresponding to each unity of derivation or distribution of waters.
\end{abstract}

Keywords: municipal segregation, irrigation, Bajo Segura, modern age, Rojales.

\section{Introducción}

Los sistemas hidráulicos pueden definirse en función de los elementos físicos y materiales que conforman su fisonomía y determinan su articulación interna, o también atendiendo al modo en que se han configurado las estructuras de poder, de control y de dominio, desde criterios más propiamente sociales y jurídico-institucionales. Ambas formas de aproximación a su estudio, entendidas desde un planteamiento dinámico, no han de considerarse alternativas, ni discurrir necesariamente por cauces paralelos, puesto que frecuentemente se entrecruzan, interrelacionan y se influyen mutuamente. A la hora de dar cuenta de las peculiaridades y funcionalidad de los diversos sistemas de irrigación, resulta conveniente, por tanto, tratar de integrar las diversas vertientes desde las que es posible proyectar análisis parciales, de cara a obtener una más profunda comprensión de los resultados de aquella interacción.

La zona de riegos del Bajo Segura, en su prolongado y complejo proceso de configuración histórica, constituye a este respecto un excelente observatorio, ya que a lo largo de los siglos se ha visto sometida a toda suerte de actuaciones y remodelaciones que, en sus 
diversas facetas, resultan reveladoras, en una perspectiva de larga duración, del desigual impacto de los diferentes factores de índole político, social, económico e incluso climático, que han ido operando en dicho escenario. Así, a lo largo de las tres centurias que convencionalmente conocemos como edad moderna, se han desarrollado en el mencionado marco espacial una serie de procesos que, de forma gradual, han ido modificando sustancialmente los parámetros heredados de época medieval, y que, lejos de fosilizarse en unas estructuras determinadas, tras la construcción del estado liberal han continuado su devenir, si bien por derroteros diferentes. A grandes rasgos, y a modo de introducción al contenido específico de la presente aportación, que se centra en el análisis del impacto que algunas manifestaciones concretas de la dinámica de segregación municipal llegaron a tener en la conformación de la jurisdicción de aguas, cabría mencionar -como mínimo- los siguientes:

En primer lugar, ha de destacarse la ampliación del perímetro de irrigación, que habría pasado de las aproximadamente 11.800 hectáreas que registra el primer padrón general de regantes conocido, correspondiente a 1536 (Bernabé, 1999a), hasta las cerca de 20.000 que contabilizó Roca de Togores en su estudio realizado casi tres siglos más tarde (Roca, 1831, 21). Sin entrar a valorar aquí los diferentes ritmos de crecimiento que jalonan esta tendencia expansiva a largo plazo, sí conviene anotar que la mayor parte de las adquisiciones se debieron a la labor desecadora y colonizadora emprendida por el Cardenal Belluga durante el segundo cuarto del siglo XVIII (León, 1962-63; Millán, 1984, 181-192) y también a una acumulación de actuaciones más modestas y dispersas, algunas de la cuales fueron llevadas a cabo a lo largo de las dos centurias precedentes en varias zonas lacustres localizadas tanto en el interior del sistema, como en sus aledaños (Bernabé, 1999b).

Junto a la extensión de la superficie irrigada a costa fundamentalmente del almarjal y, en menor medida, del secano periférico, no menos importante fue posiblemente la intensificación de los caudales sustraídos del Segura mediante dos tipos de actuaciones complementarias. Por un lado, hay que mencionar la construcción de nuevos azudes Alfaytamí, en el siglo XVI; Formentera, en el XVIII- y el alzado de alguno preexistente -en los intramuros de Orihuela-, que permitieron incrementar el volumen de agua captada por las acequias ${ }^{1}$. Por otro -y en íntima relación con el anterior-, tampoco se descuidó la remodelación, prolongación y nueva construcción las arterias de distribución, que se vieron acompañadas asimismo por la mejora de la red de drenaje, mediante la apertura de nuevas azarbes e incluso el aprovechamiento para riego de aguas muertas -el Mudamiento, Mayayo y Abanilla- que anteriormente desaguaban a través de aquéllas en el almarjal o en el cauce fluvial (León, 1962-63).

También las oscilaciones climáticas, generadoras de repentinas inundaciones, junto a los variables grados de intensidad alcanzados por las actividades dirigidas al óptimo mantenimiento de la red de irrigación -con gran incidencia en los efectos catastróficos de aquéllas-, llegaron a resultar decisivos en determinados períodos (Alberola, 2012); sobre todo, cuando se añadían los efectos del agravamiento de los problemas económicos de los regantes -especialmente en las desfavorables coyunturas del Seiscientos- y de su incapacidad para afrontar el galopante endeudamiento de las comunidades o heredamientos (Bernabé, 2013, 136-163).

\footnotetext{
1 Sobre el azud de Alfaytamí, Bernabé (2013), pp. 102-123; sobre el de Formentera, AHN: Consejos, Leg. 22.837, exp. $\mathrm{N}^{\circ}$ 6; referencia a obras de alzado en el azud de la acequia de Callosa, en Orihuela, para 1551, en AMO: Sobrecequiero, 1532-1657, ff. 315-329.
} 
La eficiencia del macrosistema de irrigación del Bajo Segura, integrado por varias piezas de diversa complejidad conformadoras de un conglomerado de azudes, acequias y azarbes de avenamiento, descansaba tradicionalmente en el equilibrio y complementariedad entre la unidad jurisdiccional, por un lado, y la fragmentación y dispersión de los núcleos de gestión y administración del riego, por otro. La primera se plasmaba en la figura del sobrecequiero de Orihuela, en tanto que juez de agua de naturaleza municipal con autoridad sobre la totalidad del término general $-\mathrm{O}$ antiguo alfoz- que le fue asignado tras la conquista. El segundo elemento remite a los heredamientos o comunidades de regantes, articulados a partir de cada unidad de derivación y distribución del agua, en un primer nivel; pero que, a su vez, admitía subdivisiones secundarias en atención a los diferentes brazales principales o arrobas en que solían ramificarse las arterias principales, o bien a las diversas entidades territoriales -lugares, aldeas y señoríos- que atravesaban, y sin perjuicio de las que llegaron a formarse asimismo a tenor de los diferentes espacios afectados por las azarbes de avenamiento $^{2}$. Así, en aplicación del principio del derecho de asociación de los usuarios interesados en una misma unidad de derivación, de distribución o de drenaje de aguas, y de la capacidad de constitución -al amparo de aquel- en órganos propios de gestión, se fue conformando una red, internamente jerarquizada y con elementos solo relativamente independientes entre sí, cuya dispersión espacial no tenía por qué comprometer la eficacia de su funcionamiento conjunto.

Naturalmente, la tendencia a la búsqueda y mantenimiento del necesario equilibrio que garantizara el óptimo aprovechamiento de ese recurso escaso pero de vital importancia, como era el agua, no podía estar exenta de conflictos; hasta el punto de constituirse esa pugna, en sus diversas manifestaciones, en un elemento consustancial al sistema, sobre todo al entrar también en juego otros usos alternativos pero no menos esenciales, como eran los relativos a la molinería (Peris, 1997, 2011). Con todo, la propia dinámica histórica y la acción de los factores de cambio social y político-institucional condujeron, al menos desde fines del Medievo, a un escenario cambiante, cuyas principales líneas de desarrollo apuntaban, a medida que avanzaba la edad moderna, fundamentalmente a dos tipos de fenómenos.

\section{Tendencias evolutivas en la época foral ${ }^{3}$}

En primer lugar, se asiste a un prolongado proceso de creciente desintegración de la unidad originaria del sistema, mediante la paulatina desmembración del término de la ciudad de Orihuela, cuyo ámbito espacial englobaba tradicionalmente la totalidad de la huerta. Por un lado, la transformación de antiguas unidades de explotación agraria de gran tamaño en algo más que meras heredades, mediante el procedimiento conocido como colonización alfonsina, sustrajo parcialmente de la antigua unidad jurisdiccional encarnada en la figura del juez sobrecequiero una serie de nuevos islotes señoriales, con aspiraciones al reconocimiento de cierta personalidad jurídica que también trascendía a materia de aguas. Las colonizaciones alfonsinas de Cox, La Granja y Redován, en el sistema de la acequia de Callosa; de Benejúzar, Jacarilla y Bigastro en el de la acequia de Alquibla; de Rafal en el de la acequia

\footnotetext{
${ }^{2}$ Referencias múltiples a juntas de regantes de diferentes acequias y brazales y de avenantes de azarbes, en AMO: Libros del Sobrecequiero, $n^{\circ} 70,71,72,73,74,75$.

3 Los párrafos que siguen, hasta que se indique otra cosa, constituyen apretado resumen, con algunas consideraciones adicionales, de Bernabé (2010), donde podrán encontrarse las pertinentes referencias documentales.
} 
Vieja de Almoradí -por la arroba de San Bartolomé- y de Molins en la de los Huertos no dejaron de menoscabar, aunque en desigual medida, el alcance real de la originaria jurisdicción depositada en el sobrecequiero oriolano.

Pero aun mayor impacto llegó a tener sobre ésta las segregaciones municipales protagonizadas por aldeas realengas tradicionalmente dependientes de la ciudad, en virtud de la adquisición de los correspondientes privilegios de universidad y de villazgo. Al ser el sobrecequiero oficio de naturaleza municipal, cada nueva entidad institucional de este tipo que surgía -Callosa y Almoradí, concretamente- conllevaba la aparición de un nuevo juez de aguas investido de jurisdicción propia en materia de riegos, para ejercer en el espacio territorial con que aquella era dotado.

Las implicaciones de este doble proceso de emancipación municipal no fueron, sin embargo, homogéneas; ni siquiera en el interior de cada modalidad. Interfirió poderosamente en este sentido la habitual falta de correspondencia entre los ámbitos espaciales dependientes de las unidades mayores de derivación y de distribución de aguas los azudes y las acequias- y los perímetros de irrigación asignados a las nuevas entidades municipales. Cuando no se produjo tal correlación, debido a que una misma acequia atravesaba diversos términos municipales, cada uno de los cuales contaba con su correspondiente sobrecequiero, la fragmentación de dicha jurisdicción obstaculizó ciertamente la administración centralizada de la justicia de aguas, pero no necesariamente la parte de la gestión ordinaria del riego controlada por las comunidades de regantes, al verse estos organismos menos afectados por aquella dispersión.

Las raras coincidencias resultantes de la superposición de los tres elementos mencionados multiplicidad de los jueces de aguas, recorrido supramunicipal de las acequias y términos municipales irrigados por varias arterias- pudieron amenazar la eficiencia del macrosistema, al generar desajustes internos susceptibles de erosionar su funcionamiento al modo tradicional. Pero quizás la presencia de otros factores contribuyera en alguna medida a contrarrestar dicha tendencia. Por un lado, se ha de valorar la posible virtualidad de las comunidades de regantes para operar, no tanto como elementos adicionales de dispersión en la gestión del regadío -al propiciar aparentemente una mayor atomización de los órganos elementales de decisión-, cuanto, fundamentalmente, como engarces capaces de proporcionar marcos de confluencia superadores de aquella fragmentación, en la medida en que podían constituirse en plataformas representativas de las grandes unidades de derivación y de distribución de aguas, por encima de las divisorias territoriales y jurisdiccionales. La persistencia de las juntas generales de herederos de las acequias de Callosa y de la Alquibla, tras los procesos disgregadores operados en su seno durante la época foral, apuntaría en esta dirección ${ }^{4}$.

Con todo, allí donde fue posible, también se trató de hacer confluir -si no íntegramente, al menos parcialmente- la segregación municipal con la dotación de un sistema de irrigación propio y diferenciado. Es lo que ocurrió a finales del Quinientos con la construcción del azud de Alfaytamí y la remodelación de la red de acequias de sus inmediaciones, al tiempo que Almoradí se independizaba de Orihuela (Bernabé, 2013); y lo que intentó -aunque infructuosamente- D. Jerónimo Rocamora varias décadas más tarde con su proyecto de abrir una acequia que condujera directamente el agua desde el cauce fluvial hasta su señorío

${ }^{4}$ AMO: Sobrecequier No 75. 1675-1895; AJPAO: Heredamiento General; Acequia de Callosa; Acequia de Alquibla. 
de Rafal ${ }^{5}$. Trataba con ello de imitar este destacado noble local la reciente y exitosa -a corto y medio plazo- iniciativa emprendida por los dominicos de Orihuela para mejorar el regadío de su heredad -luego transformada en señorío alfonsino- de Benijófar (Bernabé, 2013, 111-113); al tiempo que -hasta cierto punto- anticipaba la que, ya en la siguiente centuria, culminaría el señor alfonsino de Formentera ${ }^{6}$.

Por otro lado, la creciente intervención de la Corona propiciando una concentración de la jurisdicción de aguas -superadora de la mencionada fragmentación- y, sobre todo, asignando su control a la administración real -personificada en la figura del Asesor de la Gobernación-, trató de presentarse como la alternativa idónea para superar las fuerzas disgregadoras que operaban en el interior del sistema. Con hitos destacados en 1635, 1663 y 1699, al final de la etapa foral la dispersión de una justicia ordinaria de aguas de primera instancia, relegada a ocuparse de los asuntos secundarios o accesorios, resultaba compatible con un relativo fortalecimiento del control unitario sobre el sistema, nominalmente transferido a la asesoría de la Gobernación. No era enteramente novedoso este gradual reforzamiento de la curia de la Gobernación como instancia superior de resolución de las disfunciones inherentes a la propia dinámica del sistema, pero la reacción centrípeta que ello representaba en el plano jurisdiccional, frente a la multiplicación de células básicas de gestión del agua, tampoco habría de resultar definitiva (Bernabé, 2011).

\section{3 Época borbónica}

Abolido -en virtud de los decretos de Nueva Planta- el sistema institucional vigente antes de 1707, las nuevas directrices introducidas aprovechando la relativa ambigüedad legal en que quedó sumida la jurisdicción de aguas de origen foral significaron, en una primera fase -inaugurada en 1712-, la intensificación de la tendencia ya apuntada en la etapa anterior, al encomendarse al Alcalde Mayor de Orihuela -como subrogado en las funciones anteriormente correspondientes al ya extinto Asesor de la Gobernación- el control sobre toda la huerta del Bajo Segura y, consiguientemente, al decretarse la supresión de los juzgados municipales de aguas. Pero, como al cabo de un tiempo quedara en evidencia que no podía ser esta la mejor solución, pues habiéndose prescindido por completo de las instancias municipales, la gestión centralizada del macrosistema resultaba más lenta y onerosa -y no menos discrecional-, al cabo de una generación -1732 para Callosa, 1743 para Guardamar- o algo más -1792, para Almoradí- hubo de iniciarse la vuelta a la situación anterior, reponiéndose los antiguos juzgados (Bernabé, 2004, 2014).

Mientras tanto, los procesos disgregadores que venían operando sobre la organización del territorio, con inevitables efectos sobre los distritos hidráulicos tradicionales, tuvieron también ocasión de cobrar nuevo impulso. Por un lado, las colonizaciones agrarias emprendidas por el Cardenal Belluga en 5.000 hectáreas de almarjales ubicados en los aledaños del perímetro de irrigación tradicional, durante el segundo cuarto del Setecientos, vinieron acompañadas de la emergencia de tres nuevos núcleos de población -Nuestra Señora de los Dolores, San Felipe Neri y San Fulgencio-, con títulos de villazgo y administrados por un órgano especial -la Junta de Pías Fundaciones- que ejercía una jurisdicción privativa. Solo en aquella parte del territorio bonificado -unas 500 hectáreasque era irrigado por aguas vivas procedentes de los cauces tradicionales -expresamente

${ }^{5}$ ARV: RA: Procesos, parte III, Apéndice, no 8786.

${ }^{6}$ Vid. infra, nota 9. 
prolongados al efecto- la nueva jurisdicción de las Fundaciones podía concurrir con la tradicionalmente establecida, ejercida por el Alcalde Mayor de Orihuela. Pero, aunque no faltaron conflictos al respecto, las segregaciones municipales de las tres villas mencionadas apenas afectaron a la ordenación tradicional de la justicia de aguas, al regarse aquellas mayoritariamente mediante aguas muertas, procedentes de los azarbes de avenamiento y de los nuevos cauces abiertos para facilitar la desecación del almarjal (León, 1962-63; Bernabé, 2013).

Tampoco parece que la segregación, respecto de Orihuela, de la aldea realenga de Catral, que en 1741 adquirió a la Corona su correspondiente privilegio de villazgo, ocasionara trastornos importantes en la jurisdicción de aguas, más allá de contribuir a intensificar el proceso de fragmentación que se venía experimentando desde tiempo atrás. Y, también aquí, ello fue debido sobre todo a su concreta ubicación dentro del sistema hidráulico de la acequia de Callosa, justamente en su tramo final. Con un largo recorrido, que se extendía previamente por las huertas realengas pertenecientes a Orihuela y a Callosa y a los señoríos de Cox, La Granja, Albatera y una pequeña porción de Redován, la constitución interna de este sistema permitía la coexistencia de varios sobrecequieros, correspondientes a los distintos municipios; a los cuales se añadió, a partir de 1743, otro más para Catral, en detrimento -claro está- del alcance territorial de la jurisdicción que hasta entonces venía ejerciendo allí el de Orihuela, como municipio matriz. El recién creado sobrecequiero de Catral -cuya elección anual figura, en efecto, en las actas municipales de esta población a partir de 1743, pese a no mencionarse su existencia en el privilegio de villazgo-, debía ejercer la jurisdicción de aguas sobre la huerta constitutiva del término municipal asignado en virtud del amojonamiento entonces practicado ${ }^{7}$. Y, sólo en este sentido, el ámbito espacial de la tradicionalmente desplegada por el juez oriolano sí experimentaba un recorte sustancial. Pero, en su ejercicio ordinario, al ubicarse la huerta de Catral en la cola o último tramo de la acequia, el nuevo sobrecequiero difícilmente podía interferir en los asuntos concernientes a los regantes de arriba. La creación del nuevo juzgado, por tanto, no tenía por qué llegar a suscitar resquemores adicionales entre los restantes sobrecequieros que jalonaban la acequia de Callosa.

Y tampoco en lo referente a las comunidades de regantes la desmembración de Catral parece que introdujera cambios sustanciales en la estructura tradicional, pues ya anteriormente, al menos desde el repartimiento interno del caudal -reactualizado, con modificaciones, en 1589- por tandas o días de riego correspondientes a cada núcleo de población y señorío, cada entidad constituía un propio consell de hereters, y disponía de un síndico, sin perjuicio de la comunidad general de toda la acequia que aglutinaba a todos los consells $^{8}$. Ahora bien, tras la creación del sobrecequiero de Catral, era éste, en lugar del oriolano, quien presidía las sesiones de la "junta de herederos regantes de la acequia de Callosa en tanda de Catral", donde se adoptaban resoluciones que afectaban exclusivamente a sus integrantes.

\footnotetext{
${ }^{7}$ La publicación del privilegio de villazgo, en facsímil y transcripción, en Castrum Altum. Revista Cultural de la Asociación de Investigadores Locales de Catral, no 5, Catral, 2011, a cargo de Pura Guirao, Moisés Grau y José R. Larrosa. Entre los designados para formar el primer ayuntamiento que debía ejercer en Catral durante el año 1742 no figura ningún sobrecequiero; pero desde finales de ese año fue norma su renovación anual, que generalmente se hacía recaer sobre el alcalde ordinario saliente, tal como expresamente se afirmaba en 1768, y puede comprobarse en las tomas de posesión y juramentos correspondientes, año tras año. AMC: Libros $n^{\circ} 17$ a 21, que contiene las actas de los cabildos desde 1741 hasta 1773.

8 ARV: Real Audiencia, Procesos, parte 2a, S/655; Procesos de Madrid, S/173.
} 
La prosecución del proceso de fragmentación de la jurisdicción de aguas en el Bajo Segura es posible que también tuviera ocasión de manifestarse con motivo de las dos últimas colonizaciones alfonsinas producidas en la huerta, ya a finales de la centuria, al amparo de la reposición carolina, en 1772, del viejo privilegio foral que así lo había venido permitiendo. Durante la última década de la centuria, en efecto, los propietarios de sendas heredades denominadas la Daya Vieja y la Algorfa, respectivamente, consiguieron ver reconocida sobre las mismas la jurisdicción señorial de mixto imperio, al instalar en ellas una población superior a los 15 vecinos que exigía el fuero (Gil-Canales, 2010). Mas la parcial inmunidad en materia hidráulica que esta operación colonizadora podía conferir a señores y vasallos resultaba algo distinta en uno y otro caso.

Así, la Daya Vieja se regaba íntegramente de una acequia propia que se nutría del regolfo generado en el denominado azud de Rojales; de donde -como se dirá más adelantederivaban también otras arterias (Roca, 1831). Su situación resultaba, por tanto, muy parecida a la existente en el señorío de Benijófar, que también irrigaba de un cauce propio e independiente; y, parcialmente, incluso a la de Formentera, desde que -posteriormente- el señor del lugar consiguiera vincular su acequia Nueva a un nuevo azud construido en colaboración con el anterior?. La Algorfa, en cambio, debía su irrigación al caudal arrastrado por la acequia de la Alquibla, que, con origen en Orihuela, recorría además otros tres señoríos previamente -Bigastro, Jacarilla y Benejúzar- y una parte del término realengo de Almoradí; por lo que la capacidad de control señorial sobre el agua resultaba en este caso algo más reducida, al tener que compartirla con otras entidades municipales. Por otro lado, el hecho -relativamente insólito en casos de esta naturaleza- de que tanto en la Daya Vieja como en la Algorfa los vasallos no gozaran de la condición de "herederos" -O regantes- de pleno derecho, al ser simples arrendatarios en lugar de enfiteutas (Gil-Canales, 2010), introducía un nuevo elemento diferenciador con respecto a la mayoría de los señoríos tradicionales, con alguna repercusión en materia de jurisdicción de aguas. Tal pudo ser, por ejemplo, la inexistencia -por innecesarios- de sobrecequieros y de juntas particulares de regantes, en ambos casos. En un balance conjunto, por tanto, no puede afirmarse que estas tardías colonizaciones alfonsinas de finales del siglo XVIII alterasen de forma significativa el mapa de los juzgados de aguas del Bajo Segura.

\section{Impacto de la segregación de Rojales}

Caso muy distinto, en esta dinámica disgregadora del espacio jurisdiccional del regadío, fue el representado por la desmembración de la aldea realenga o barrio de Rojales respecto de la villa de Guardamar. Expedido en 1773, el privilegio de villazgo obtenido por Rojales vino precedido de una serie de movimientos segregacionistas que se remontan, al menos a $1749^{10}$. Tratando de contrarrestar los informes presentados entonces por los habitantes de la aldea ante el Consejo de Castilla, en un memorial dirigido al mismo por el síndico de Guardamar en 1751 se exponía ya, entre los perjuicios que la pretendida segregación ocasionaría, que "quedaría como inútil y estéril lo que a dicha villa se le reservara, por faltar

\footnotetext{
${ }^{9}$ La construcción del azud de Formentera -para irrigar aproximadamente las dos terceras partes de dicho señorío alfonsino, fundado en 1691 - se produjo en 1756, merced a la colaboración entre su titular y el de Benijófar, que corrió con una parte de los gastos. La precariedad de la obra original determinó un posterior y definitivo reforzamiento y alzado en 1796, lo que suscitó la oposición de los regantes del azud de Rojales, situados río abajo. AHN: Consejos, Leg. 22837, exp. $\mathrm{N}^{\circ} 6$.

10 AHMG: Cabildos de 1749, sesiones de 16 de septiembre, 20 de octubre y 15 de noviembre; Cabildos de 1750, sesiones de 12 y 21 de enero.
} 
a sus tierras el beneficio del riego, porque en dicho barrio se toman las aguas y desde allí se encaminan a sus heredades" 11 . Y, tal como se encargaría de ratificar la experiencia posterior, no resultaban infundados tales temores.

La huerta de Guardamar-Rojales formaba tradicionalmente un espacio unitario e indiferenciado, que se irrigaba íntegramente a través de varias acequias tributarias de un azud construido en la población de Rojales. Por la margen izquierda, las acequias denominadas la Comuna, los Huertos y la Alcudia distribuían el líquido elemento por un total aproximado a las 1.100 hectáreas a finales del Setecientos; mientras que por la estrecha huerta de la margen derecha la acequia de la Bernada apenas beneficiaba a unas $90^{12}$. Desde época medieval, la jurisdicción sobre este sistema era ejercida por el sobrecequiero de la villa de Guardamar, al tiempo que permanecía constituida una comunidad de regantes conjunta para todos los propietarios de la huerta tributaria del azud ${ }^{13}$. Al estar ubicado el barrio de Rojales aguas arriba, cualquier asignación de término propio que se realizara a su favor como consecuencia de una posible segregación municipal implicaba relegar el término de Guardamar a una posición subalterna, pues su huerta permanecería en el tramo inferior de todas las acequias y quedaría mediatizada la posibilidad de acceso directo al azud y a la cabecera de aquellas. De ahí la tenaz oposición que ésta mostrara ante los más leves indicios de separación.

Los moradores y propietarios de huerta en las inmediaciones de Rojales, por el contrario, aspiraban a liberarse de la jurisdicción de un sobrecequiero que -según sus apreciacionesdefendía más los intereses de los regantes de la villa que los del barrio. Y aunque en octubre de 1751 la Cámara de Castilla, en vista del informe de la Audiencia de Valencia, declaró en contra de sus pretensiones, no habría de transcurrir mucho tiempo antes de que aquéllos volvieran nuevamente a la carga. Así, cuando en 1769 retomaron la intentona independentista, que en esta ocasión sí se saldó con el éxito esperado -al cabo de cuatro años y a cambio de un servicio a la Monarquía próximo a los 150.000 maravedíes de vellón, no olvidaron la inevitable referencia al tema en cuestión. En el privilegio de villazgo obtenido por Rojales en 1773 se recogía expresamente, a la hora de mencionar los agravios de que venían siendo objeto sus moradores por parte de "la justicia de la villa de Guardamar", el que "les impedía el uso de las aguas los días que por sus estatutos les estaba concedido" $" 14$.

El privilegio de villazgo de Rojales, que en su parte dispositiva no se alejaba mucho de lo dispuesto en este tipo de concesiones -como la ya anteriormente referida, correspondiente a Catral, entre otras-, ignoraba toda referencia expresa a la instauración del oficio de sobrecequiero, pues solo aludía a la facultad vecinal para que "junta en su Ayuntamiento, pueda nombrar y proponer (según lo hacen las demás villas del Reino de Valencia) personas para que sean Alcaldes Ordinarios, Regidores, Procurador General y Alcaldes de la Hermandad, para su gobierno". Sin embargo, el primer alcalde ordinario de Rojales al que se dio posesión de inmediato por parte del comisario real allí expresamente enviado, debió entender que la justicia de aguas formaba parte de la jurisdicción genérica, civil y

\footnotetext{
11 AHMG: Cabildos de 1751, memorial sin fecha, hacia octubre de ese año, s. f.

12 Según recuento de Roca de Togores, en la década de 1820 ascendían a 10.038 tahullas -1.195 hectáreas- y a 756 tahúllas -90 hectáreas-, respectivamente.

13 Algunas copias de actas de sesiones celebradas por dichas Juntas, bajo la presidencia del sobrecequiero, para principios del XVII, en AMO: Sobrecequiero, $N^{\circ} 73$; Sobrecequiero, $N^{o} 76$.

${ }^{14} \mathrm{El}$ privilegio de villazgo, en AHN: Consejos, Lib. 2504, ff. 365-372, donde se recogen asimismo referencias a los precedentes mencionados.
} 
criminal en primera instancia, recién adquirida con el título de villazgo, en virtud de las diligencias practicadas a tal efecto en 24 de julio ${ }^{15}$; y posiblemente, incluso llegara a disponer algunas primeras actuaciones en materia de riegos. De hecho, también en Guardamar se había llegado a incorporar el conocimiento de los temas hidráulicos a la máxima autoridad municipal, en lugar de permanecer depositado en un oficial distinto ${ }^{16}$.

Todo ello explicaría que el 9 de agosto de ese mismo año, el alcalde ordinario de Guardamar, Manuel Blasco, intitulándose al mismo tiempo "juez sobrecequiero", decidiera expedir exordio, con acuerdo de su asesor, dirigido a la máxima autoridad de Rojales, Josep Lillo, para que se abstuviera de intervenir en asuntos de aguas. Se temía en Guardamar que desde la nueva villa se procediera a "alterar las tandas y repartimientos que tienen dichos heredamientos para el uso y buen régimen de sus aguas". Y, como en Rojales se decidiera ignorar el asunto, en 17 de septiembre volvía a presentar Guardamar nueva escritura, ahora ya conteniendo acusaciones concretas, ante el Consejo de Castilla. Se expresaba en ella los perjuicios ocasionados desde la reciente concesión al antiguo barrio del título de villazgo, de modo que "experimenta la huerta de esta villa de Guardamar, los dueños de sus respectivas haciendas y los arrendadores la mayor ruina y deterioración en sus plantados y frutos, a causa de que la Justicia de la de Rojales, por ser los Alcaldes y Regidores hacendados, invierten las tandas de las aguas y las consumen a beneficio de sus huertas, sin dejar pasar a la de Guardamar, situada a la parte inferior, la precisa y pertinente por su dotación y que han disfrutado de inmemorial tiempo, tomándose el conocimiento en el manejo de ellas de hecho y en perjuicio de la real jurisdicción que ejerce el exponiente". Cundía la alarma en Guardamar por el deterioro patrimonial que ello podía generar entre los propietarios, pues "faltándoles el precisso riego de agua dulce desmerecerían las tierras de su intrínseco valor"; al tiempo que se desconfiaba de la adecuada gestión de las acequias, ya que "siendo unas mismas y continuadas desde la toma de dicha presa hasta su desagüe al Río y término de Guardamar, se verificarían dos Juzgados, con dos cabezas en cada una acequia". Concluían solicitando, por tanto, la unificación de la justicia de aguas y su reasignación a Guardamar -como quería la tradición- y "porque como últimos regantes ha de vigilar el Juez Sobrecequiero sobre la observancia de las tandas y reparticiones y que los primeros regantes no abusen de ellas ni las arrojen a los edificios de aguas muertas, pues de otro modo no podrán regar sus tierras situadas en inferior parte"17.

Naturalmente, la parte contraria no solo negó las acusaciones que se le imputaban, sino que defendió la posesión jurisdiccional recién adquirida, al tiempo que informaba del nuevo organigrama con que, al amparo de ella, se había dotado, solo en unas pocas semanas; y de la mayor vigilancia que se ejercía ahora sobre el riego. En réplica ofrecida por Rojales el 8 de octubre, se aseguraba, entre otras ventajas, "que desde que se dio a esta real Justicia y Regimiento la posesión seu quasi de las aguas del Rio Segura, sus edificios y tomas, ha permanecido en ellas quieta y pacíficamente sin contradicción de persona alguna, y en su virtud ha procedido al emplazamiento de los respectivos heredados para el nombramiento y elección de síndicos, subsíndicos, electos y demás empleos que aquellos han estimado

\footnotetext{
15 AHN: Consejos: Leg. 22.753, f. 186.

16 Así consta claramente para 1749, cuando en la toma de posesión de los cargos de alcalde primero y de alcalde segundo, ambos sujetos fueron designados al mismo tiempo para ejercer como "juez de aguas de este término y jurisdicción”. AHMG: Cabildos de 1749, sesión de 3 de febrero.

17 Toda esta información y la que sigue, salvo expresa indicación en contrario, procede de AHN: Consejos, Leg. 22.753. Ahorro sucesivas referencias a las diversas unidades documentales que componen este expediente, perfectamente localizables e identificables en el original a partir de la datación y demás pormenores que menciono en el texto.
} 
necesarios, celebrando a su efecto los correspondientes congresos y juntas, y presidiéndolas según estilo, con otros actos de jurisdicción en cuanto al Juzgado de aguas, sin que se le haya perturbado ni molestado en ninguno de ellos".

Entablado de este modo el pleito correspondiente, una provisión del Consejo de Castilla, de primero de febrero de 1774, recogió parcialmente las aspiraciones de Guardamar, ordenando a Rojales no realizar "por ahora novedad alguna en el uso de las aguas que se expresan, siguiendo el riego y uso de ellas del mismo modo que se practicaba antes de que a esa villa se pusiese en posesión de su privilegio de villazgo". Pero dejaba sin aclarar el asunto principal, relativo a la duplicidad de juzgados de aguas. Y tampoco las posteriores instancias realizadas por Rojales, durante el mes siguiente, ni la solicitud del expediente por parte de Guardamar para alegar en consecuencia, en julio de 1775, contribuyeron decisivamente a ello. Lo más seguro es que a partir de entonces coexistiera una doble jurisdicción de aguas, con radio de acción respectiva sobre el territorio de huerta asignado a cada término municipal. Pero ello significaba, además de alimentar la potencial conflictividad, reconocer la supremacía de Rojales en el control sobre el sistema, al amparo de su inmejorable posición. Con todo, era mera cuestión de tiempo que volviera a replantearse el asunto no definitivamente resuelto.

Así, cuando en abril de 1791 los regantes de Rojales por las acequias de la Alcudia y de los Huertos no respetaron el turno de riego correspondiente a Guardamar -ocho días de una tanda de quince-, alegando que no existía reparto establecido, sino que cada cual utilizaba el agua en función de sus necesidades, saltó la chispa que habría de conducir a una reconsideración de la duplicidad de juzgados. En su alegato ante el Consejo expuso Guardamar no solamente los abusos concretos -hurtos de agua- recientemente perpetrados, con la aquiescencia del alcalde de Rojales, sino también su incuria en la obligación de realizar las mondas y limpieza de los cauces en los tramos superiores, provocando con ello obturaciones y colmataciones en los lechos, que iban en claro detrimento de los caudales discurrentes aguas abajo. Tras razonar acerca de las diferentes desventajas que se derivaban para Guardamar de la existencia de un juez de aguas en Rojales, solicitaban al Consejo "se cometa y encargue con palabras claras, que no puedan interpretar a su arbitrio los de Rojales, el conocimiento privativo de todas las causas de aguas, mondas, limpias y demás, como lo tenía antes, al sobrecequiero de Guardamar, a quien deberán acudir con sus quejas los vecinos de una y otra villa en solo el punto de aguas y riegos".

Atendió a las pocas semanas el Consejo de Castilla esta pretensión y, sin que sirvieran de mucho las protestas y razones en contra elevadas por Rojales en su correspondiente alegación, a finales de mayo encomendó al juez real más cercano -el Alcalde Mayor de la villa de Callosa de Segura- su puntual cumplimiento, mediante la entrega al alcalde ordinario de Guardamar de las llaves que daban acceso al pequeño edificio donde se custodiaba el tablacho o compuerta que, en las proximidades del azud, regulaba el paso del agua desde el río al sistema de acequias. Convertidas en todo un símbolo del poder hidráulico y del control sobre el riego, las llaves conferían a su tenedor plena capacidad sobre las decisiones a adoptar en caso -nada infrecuente, dado el régimen pluviométrico de la zona, plenamente inmersa en un clima semiárido de escasas precipitaciones, pero de gran intensidad horaria, hasta convertirse fácilmente en torrenciales- de que cualquier alteración extrema del caudal del río amenazara con acarrear graves problemas a la huerta.

El forzado traspaso de llaves, formalizado el primero de junio de 1791, al alcalde ordinario y juez sobrecequiero de Guardamar, Josep Hernández Barber, no podía dejar indiferente a 
los de Rojales, que aprovecharon una nueva y severa manifestación de la extrema irregularidad del caudal del Segura para plantear los perjuicios que aquella decisión podía ocasionar en su huerta, dada la distancia a que se encontraba Guardamar -como sede judicial-, y el carácter imprevisible del régimen pluviométrico del río, que exigía resoluciones de rápida ejecución. Siempre proclive a dejar pasar más caudal del necesario, para facilitar así su llegada hasta los confines de la huerta de Guardamar, el juez de aguas se había excedido en sus previsiones alzando el tablacho más de lo conveniente; de modo que una crecida sobrevenida por sorpresa el día 3 de junio había llegado a inundar gran parte de la huerta de Rojales, arrasado algunas cosechas e inutilizado más de una acequia debido a las cantidades de lodo y arenas arrastradas por el río. Era el tipo de inconvenientes que se derivaban de ese control remoto sobre el caudal establecido por la provisión del Consejo favorable a Guardamar. Y así se hizo constar por Rojales en Madrid, en espera de obtener resolución a favor.

Obviamente, no reconocían en Rojales problema alguno en esta concurrencia de juzgados expresamente rechazada por Guardamar; y mencionaban al respecto ejemplos cercanos que mostraban la viabilidad de la gestión del riego en situaciones afines, asentadas además en una larga tradición. Así "sucede y está establecido en las Acequias principales de toda esta huerta, v.g. las llamadas Alquibla, Almoradí y Callosa, cada una de ellas pasa y fructifica seis o siete términos, y cada Justicia conoce sobre las aguas del suyo, pero las llaves del tablacho están baxo el dominio del Juez en cuya jurisdicción está la boquera (....) y así lo ha executado siempre la Justicia de esta villa desde el año 73, en que tomó la posesión de las llaves del tablacho de la boquera por donde se riega su huerta y la de Guardamar". Plenamente conscientes, por tanto, de que "la posesión de las llaves del tablacho es el punto crítico en que consiste el que los de Guardamar no vuelvan a utilizar con tiranía su dominio contra este pueblo", pues "en su mano está el hacer pobres o ricos a los labradores de esta huerta", solicitaban los de Rojales -en escrito de 10 de junio- la recuperación de las llaves y declaración formal del Consejo sobre "que el privativo conocimiento de las aguas [por parte del de Guardamar] no se extiende a otro territorio que el de su huerta, prohibiéndole que ejerza jurisdicción en esta villa sobre dicho asunto de aguas, ni otro".

Mientras tanto, al tiempo que se prodigaban por ambas partes determinados actos de sabotaje en las prácticas de irrigación, tampoco faltaron memoriales, declaraciones y acusaciones concretas sobre el nefasto protagonismo de determinados interesados en avivar la polémica, que en nada contribuían a arreglar la situación. Acusaban los de Rojales de tiranía a los hermanos Pascual y Joaquin Aracil, que controlaban la escribanía del ayuntamiento de Guardamar, de ser los principales instigadores del conflicto, y al alcalde Domingo Claramunt, su destemplado ejecutor. Y desde Guardamar se señalaba a la familia Pastor, "pues exerciendo regularmente el empleo de Alcaldes Damián Pastor, su hijo y otros de su contemplación y devoción, y teniendo como tienen dicho Pastor, sus hijos y yerno mucha porción de tierras propias y arrendada la huerta de Rojales, que llegará con corta diferencia a dos mil tahúllas, no es mucho que favorezcan estas contravenciones y atentados". De este modo, si por parte de Rojales se temía "de un momento a otro la riña y la conmoción”, los de Guardamar contemplaban la situación "en disposición de suceder algunas desgracias".

En este contexto, haciendo gala de la autoridad con la que había sido -si no investidorecientemente fortalecido, el alcalde ordinario y juez de aguas de Guardamar decidió trasladarse a Rojales para ordenar allí la publicación, el 25 de junio, del reglamento de riego 
vigente vertido al idioma castellano -el confeccionado en 1624 por Mingot $^{18}$, al tiempo que la promulgación de una serie de seis capítulos aclaratorios adicionales, orientados a salvaguardar los intereses de los regantes de abajo. Se trataba con ello, además, de dejar plenamente sentado quien mandaba en la huerta.

En espera de la decisión del Consejo, el verano transcurrió en un clima de relativa tranquilidad entre los regantes y las autoridades de ambos pueblos vecinos; hasta que aquél acabó decretando el 25 de septiembre, una vez ponderadas las alegaciones de ambas partes, que fuera el Alcalde Mayor de Callosa -como oficial real e imparcial- quien se incautara provisionalmente de las llaves del tablacho, acometiera el reparto de las aguas con arreglo a las ordenanzas vigentes y vigilara su estricta aplicación y cumplimiento, especialmente en lo concerniente al mantenimiento de la infraestructura hidráulica. Un vez más, empero, quedaba sin resolverse con suficiente claridad el asunto capital.

En vista de que iba a resultar difícil evitar que, tarde o temprano, la balanza se inclinase de un solo lado, se fue abriendo paso la idea de buscar una solución salomónica capaz de satisfacer a ambas partes en litigio; lo que sólo era posible con la activa participación de los sectores más directamente involucrados y, en definitiva, los grandes propietarios de la huerta. Así pues, atendiendo a que "las personas más condecorosas y circunstanciadas de ellas [ambas villas], que maior interés podían tener y tenían en las aguas para los riegos de sus respectivas tierras, estaban dispuestas a avenirse, transigirse y concordarse (...), como lo manifestaron algunos sujetos que movidos del buen celo y deseosos de la paz entre villas tan próximas y confinantes, apetecían y solicitaban remover todo motivo del menor disgusto a sus habitantes", el Alcalde Mayor de Callosa ofreció su mediación para tratar de elaborar una concordia satisfactoria que dejara zanjado definitivamente el asunto en lo venidero. Por consiguiente, tras "varias conferencias entre los primeros, más condecorados y mayores interesados en los riegos de las propias aguas, a presencia del Alcalde Mayor", se llegó finalmente a una transacción expresada en forma de diez capítulos. El 20 de enero de 1792 ya estaban redactados para su debate y aprobación por parte de ambos ayuntamientos y por la Junta General del Heredamiento, como órgano representativo de la totalidad de los regantes sin cuya conformidad nada ofrecía garantías de poder salir adelante.

El 15 de febrero se celebraba, pues, en Guardamar dicha Junta, donde -tras largas sesiones de mañana y tarde, a las que asistieron 55 propietarios- se aprobaron varias modificaciones y adiciones al texto originario, con tal de recomponer algunas situaciones ventajosas para Rojales inicialmente previstas, y se nombraron comisarios con poderes para formalizar la escritura definitiva. Pocos días más tarde era finalmente ratificada la versión resultante por los respectivos cabildos municipales y entraba en vigor, tras la correspondiente decretación por el Consejo de Castilla. Quedaba así resuelta, por la vía de concordia entre los sectores implicados -única posible, a la vista de la ambigüedad y provisionalidad de las resoluciones del Consejo-, la disputa originada en materia de aguas por la segregación municipal de Rojales dos décadas atrás.

En un balance general de lo acordado, son varios los aspectos a destacar. En primer lugar, quedaba consagrada la duplicidad de juzgados, cada uno con jurisdicción propia en su correspondiente término municipal y durante los días en que tuviera asignada su tanda, con

\footnotetext{
18 Los estatutos de aguas de D. Jerónimo Mingot, integrados por 32 capítulos, fueron promulgados en valenciano en 1624. Vertidos al castellano hacia 1712, fueron impresos recientemente (en 1982) por ambos Juzgados de Aguas, con estudio introductorio de Agustin Nieto.
} 
independencia de la vecindad de los querellantes, pero haciendo prevalecer el criterio temporal sobre el espacial. De este modo, en caso de apropiación indebida de agua perpetrada en el término municipal de Rojales durante los días de tanda de Guardamar, tocaba al juez de este último su conocimiento. Asumiendo la tradición, se propuso inicialmente que la tanda de Rojales constara de seis días y medio, o 156 horas, a contar desde las seis de la mañana; y a continuación -a las seis de la tarde del séptimo díacomenzaría la tanda de Guardamar, cuya duración se establecía en siete días y medio, o 180 horas, al ser algo más extensa su huerta. Asímismo, se propuso que cada juzgado gozara de plena autonomía para decidir la distribución interna entre las tierras de su distrito. Pero, durante el debate posterior habido en la Junta General del Heredamiento, esta propuesta resultó profundamente modificada, al imponerse la decisión mayoritaria de llevar a cabo un recuento global de las tahúllas irrigadas en todo el sistema y, en función de su extensión, asignar el tiempo correspondiente a cada parcela, independientemente del término municipal al que perteneciera. El reparto se realizaría, por consiguiente, mediante una simple operación matemática y "sin que por tener más o menos altura las de un pueblo que las de otro pueda pretenderse que se execute la distribución bajo de otros términos que el propuesto"; pero tomando en consideración, a dichos efectos, las cenias o artefactos elevadores actualmente existentes.

Problema especial era el que se planteaba en la acequia de la Alcudia, puesto que, a diferencia de la Comuna y la de los Huertos, nunca había estado sujeta a tanda, sino que tradicionalmente se practicaba en ella el riego libre y discrecional, en función de las necesidades de cada cultivo. Esta modalidad privilegiaba claramente a los regantes de los tramos superiores y podía tener plena justificación en acequias caudalosas, como supuestamente- era el caso de la Alcudia. En la propuesta inicial se había tratado de no innovar la práctica tradicional, de modo que el mismo día y hora en que se iniciase la tanda para las otras acequias, comenzarían a regar también por la cabecera de la Alcudia, por estricto orden de ubicación, tomando los regantes el agua que necesitaren durante el tiempo que considerasen oportuno. Pero como ello conllevaba el evidente riesgo de que transcurrieran los catorce días de la tanda sin que los regantes del tramo final hubiesen tenido aun oportunidad de acceder al agua, para evitar los problemas que estas situaciones podían generar y no perjudicar a las tierras de abajo, se decidió introducir una modificación. Así pues, en casos especiales de inusitada escasez de agua en dicha acequia, "se ha de hacer un repartimiento entre ellas, por horas o partidores, de los catorce días de la duración de la tanda (...) extrajudicialmente y con arreglo solo a los padrones de mondas (...), teniendo en consideración que este caso podrá ocurrir rara o ninguna vez”. Llegado el caso, correspondería a los síndicos y jueces de ambos heredamientos, conjuntamente, la decisión de "declarar si se verificara o no dicha escasez" y activar en consecuencia el mecanismo de reparto.

La duplicidad administrativa se hacía extensible también a las tareas de limpieza y mantenimiento de la infraestructura hidráulica, quedando obligado cada juez a procurar la óptima realización de las mondas de acequias y azarbes en los plazos y calendario previstos, dentro de su distrito - a costa de los respectivos regantes-, pero contando con la expresa conformidad de dos peritos de la villa vecina, que así debían certificarlo. Finalmente, el crucial asunto de la tenencia de las llaves del tablacho de la boquera se resolvía haciendo un duplicado y entregando una a cada juez para que la utilizara exclusivamente durante los días de la tanda correspondiente a su distrito. Únicamente en caso de repentina avenida o urgente necesidad y a efecto "de precaver el daño" de posible inundación, quedaba 
autorizado a hacer uso de aquella el juez de Rojales, por su inmediatez, aunque fuese en tiempo correspondiente a la tanda de Guardamar.

Quedaba, de este modo, zanjada la polémica suscitada años atrás y sentadas las bases para un entendimiento que hiciera posible la concurrencia de dos jueces de aguas de similar jurisdicción sobre un sistema hidráulico tradicionalmente unitario. Más allá del protagonismo reclamado por las autoridades valedoras de determinados intereses vecinales, o por los representantes de la Corona, habría de ser finalmente el colectivo de regantes, a través de la Junta General del Heredamiento, el que aportara -con sus modificaciones y adiciones a los capítulos originales- la única solución viable. Si tenemos en cuenta, por otro lado, -a falta de datos sobre la distribución de la propiedad- que el censo de Floridablanca recoge -para 1788- un total de 96 labradores entre Guardamar y Rojales -algunos de los cuales debían tener sus heredades en el campo,- no parece, finalmente, que aquellos órganos asamblearios de gestión del agua tuvieran demasiados problemas para erigirse en genuinos representantes de una cualificada mayoría de regantes.

\section{Agradecimientos}

Este trabajo ha sido realizado en el marco del Proyecto de Investigación HAR2011-27062, financiado por el Ministerio de Ciencia e Innovación.

\section{Referencias}

Alberola, A. (2012): Quan la pluja no sap ploure, PUV, Valencia

Bernabé, D. (1999a): "Aspectos sociales del crecimiento agrario valenciano en tiempos de Felipe II", Felipe II y el Mediterráneo I- Los recursos humanos y materiales, Sociedad Estatal para la Conmemoración de los Centenarios de Felipe II y Carlos V, Madrid, 1999, vol. I, pp. 179193

Bernabé, D. (1999b): "Insalubridad y bonificaciones de almarjales en el Bajo Segura antes de las Pías Fundaciones de Belluga (siglos XVI-XVII)", Revista de Historia Moderna, $\mathrm{n}^{\circ}$ 17, pp. 45-71

Bernabé, D. (2004): "Repercusiones del cambio dinástico sobre los Juzgados de Aguas del Bajo Segura", Alvar, A. Contreras, J. y Ruiz, J.I. (eds.): Política y cultura en la época moderna, Universidad de Alcalá-F.E.H.M., Alcalá de Henares, págs. 419-430

Bernabé, D. (2010): "Regadío y transformación de los espacios jurisdiccionales en el Bajo Segura durante la época foral moderna", Revista de Geografía, no 53, págs. 63-84

Bernabé, D. (2013): Almoradí en la Edad Moderna (SS. XVI-XVIII), Ayuntamiento de Almoradí, Almoradí

Bernabé, D. (2014) "Extinción y reposición de los juzgados de aguas en el Bajo Segura durante el siglo XVIII", Homenaje al Dr. D. Antonio Gil Olcina, Universidad de Alicante, Alicante

Gil, A. y Canales, G. (2010): Residuos de propiedad señorial en España, Universidad de Alicante, Alicante 
León, T. (1962-63): “Aportación al estudio de la colonización de la Vega Baja del Segura”, Anales de la Universidad de Murcia, vol. 21, 1-2, pp. 98-140

Peris, T. (1997): "La conflictividad hidráulica en el País Valenciano entre los siglos XII y XVIII”, Áreas, no 17, pp. 43-60

Peris, T. (2011): "Los conflictos por el agua en el País Valenciano durante la etapa feudal: el ejemplo de los molinos", Sociedad Española de Historia Agraria, no 11

Roca de Togores, J. (1831): Memoria sobre los riegos de la huerta de Oribuela, Benito Monfort, Valencia

\section{Fuentes documentales}

AHMC: Archivo Histórico Municipal de Catral

AHMG: Archivo Histórico Municipal de Guardamar del Segura

AHN: Archivo Histórico Nacional

AJPAO: Archivo del Juzgado Privativo de Aguas de Orihuela 